${ }^{1}$ Graduate Program in Dentistry, School of Dentistry, University of Vale do Taquari (UNIVATES); Lajeado, RS, Brazil.

${ }^{2}$ Graduate Program in Dentistry, School of Dentistry, Federal University of Pelotas, Pelotas, RS, Brazil.
Corresponding author: Luiz Alexandre Chisini DDS, MS, PhD Professor (School of Dentistry University of Vale do Taquari) University of Vale do Taquari, School of Dentistry, Graduate Program of Dentistry

Address: 171, Avelino Talini St Lajeado - RS - Brazil 95914-014 Phone: (55) 53981121141E-mail: alexandrechisini@gmail.com

Received: August 29, 2020

Accepted: December 8, 2020

\section{Is obesity associated with tooth loss due to caries? A Cross-sectional study}

\author{
Luiz Alexandre Chisini ${ }^{12^{\star}}$ (iD, Ana Beatriz de Lima \\ Queiroz $^{2}$ iD, Filippe Vareira de Lima² ${ }^{2}$, Lucas Jardim \\ da Silva² (iD, Mariana Gonzalez Cademartori² iD, \\ Francine dos Santos Costa ${ }^{1}$ iD, Flávio Fernando \\ Demarco $^{2}$ iD, Marcos Brito Corrêa ${ }^{2}$ (iD
}

Aim: To investigate the association between obesity, overweight, and tooth loss due to caries among university students of (Federal University of Pelotas) in southern Brazil. Methods: A cross-sectional study with all first-year students who regularly enrolled in the first semester of 2016 who were invited to respond to a self-administered questionnaire contain socioeconomic and demographic; psychosocial; oral health; behavioral questions. The body mass index (BMI) was calculated through the self-reported data of weight and height. The main outcome of the present study was determined by the person's that answer having had at least one tooth extracted due to caries. A Poisson regression using a backward stepwise procedure was performed. Two models were tested: i) including socioeconomic and behavioral variables; ii) without behavioral variables. Results: From 3,237 eligible students, 2,089 (64.5\%) participated in the present study. Almost 23\% of students presented overweight and $8.4 \%$ obesity, whereas 362 individuals (17.5\%) reported having had at least one tooth extracted due to caries. Regarding the final model adjusted by behavioral variables, it was observed that obese university students presented a $32.0 \%$ higher prevalence of tooth loss (PR=0.32,Cl95\%[1.17-1.49]). However, overweight was not associated with tooth loss in the present sample. When the model was not associated with behavioral variables, overweight was associated with tooth loss ( $P R=1.44 ; C 195 \%[1.15-1.81]$ ), just as obesity (PR=2.13; Cl95\%[1.63 - 2.78]). Conclusions: Obesity and overweight were associated with tooth loss due to caries in the present sample of university students.

Keywords: Epidemiology. Tooth loss. Dental caries. Obesity. 


\section{Introduction}

Obesity is a health disturb featured by fat surplusage due to unhealthy eating habits, sedentary lifestyle, genetic, social, and behavioral aspects, which affects people's quality of life in many ways' ${ }^{1}$. This disorder is frequently associated with comorbidities such as hypertension, osteoarthritis, certain types of cancer and diabetes, and caries ${ }^{2-4}$. According to the World Health Organization (WHO), obesity is increasing worldwide, affecting both developed and developing countries ${ }^{1,5}$. From an economic perspective, obesity is also an impairment owing to great direct medical expenditure and drugs' costs ${ }^{1,5}$.

The diet of individuals is a determinant in obesity occurrence, mainly due to the high levels of lipids, carbohydrates and sugars intake ${ }^{6}$. Similarly, studies have presented solid evidence of the role of sugar consumption on dental caries experience ${ }^{7,8}$ which is a common cause of obesity ${ }^{4,6}$, and can culminate in tooth loss. In this way, systematic reviews have reported contradictory results between the association of obesity and dental caries, mainly based on children and adolescents samples ${ }^{4,6}$. Mainly, studies that investigate the association between caries and obesity were performed with children ${ }^{9-13}$.

A recent study showed an elevated prevalence of obesity among university students ${ }^{14}$. Few studies report how obesity correlates with caries and tooth loss in the undergraduate population, which is relevant considering the high prevalence of overweighed students ${ }^{14}$. Oppositely to studies that report the relation between periodontal disease and overweight, which already have concise results in literature ${ }^{15}$, the possible association between tooth loss due to caries and obesity is not well established yet ${ }^{9,10,16,17}$. Thus, the purpose of this study was to investigate if there is an association between obesity and tooth loss due to caries among university students in southern Brazil. The present study hypothesizes that obesity and overweight are associated with tooth loss.

\section{Materials and methods}

The present study was reported following the recommendation of Strengthening the Reporting of Observational Studies in Epidemiology (STROBE) for cross-sectional studies. Full details concerning the methods of the present study's baseline have been published previously 18,19 .

\section{Ethical issues}

The institution (UFPel) and Research Ethics Committee of the School of Medicine / UFPel approved this study under protocol 49449415.2.0000.5317.

\section{Setting and study design}

A cross-sectional analytical study was carried out with students from Federal University of Pelotas (UFPel). The sample consisted of students that joined the university in the first semester of 2016, excluding distance learning courses (626 students). The average new enrollments of UFPel by semester is 3,000 students. Thus, we applied a self-reported questionnaire with first-year students of UFPel. Previously, a pilot questionnaire was tested in other students ( $n=100$ from the second semester) from five courses selected randomly. The official questionnaire was improved after the pilot and the meantime spent to answer was 20 minutes. 


\section{Participants (eligible and non-eligible participants)}

All students regularly enrolled in the first semester of 2016 at UFPel composed the eligible sample. First-year students were searched in their respective academic units with the authorization of academic directors and professors. The questionnaires were applied before or after lessons, respecting professors' preference. Students that were not regularly enrolled in the course and students from distance learning courses were excluded from the sample.

\section{Data collection}

The fieldwork team was composed of undergraduate and graduate students under the supervision of Professors of UFPel Dental School. The participants were part of the oral health epidemiology study group (EpiBucal). The questionnaire was constructed in the EpiBucal meetings. The final questionnaire was self-administered designed, presented 74 multiple-choice questions which were divided into 5 wide blocks: 1) Socioeconomic and demographic; 2) Psychosocial; 3) Oral health; 4) Behavioral of oral health; 5) Drugs use.

\section{Outcome}

The outcome of the present study was the self-report of tooth loss due to caries. The individual answered if he or she had at least one dental extraction due to dental caries, in the question: "Have you ever had a tooth extracted because it was affected by caries?" Yes or No were the possible answers.

\section{Exposure}

The body mass index (BMI) was calculated using the self-report of current weight (in kilograms) and height (in meters). These variables were assessed as continuous and were posteriorly converted to categorical, as recommended by the World Health Organization criteria ${ }^{20}$. The $\mathrm{BMI}$ is defined as the weight divided by the square of the height $\left(\mathrm{kg} / \mathrm{m}^{2}\right)$. The established cut-off points ${ }^{20}$ were the following: a) Eutrophic $(\mathrm{BMI}<25)$; b) Overweight (BMI between 25 and 30); and c) Obesity (BMI>30.0).

\section{Confounding/mediator variables}

Two models were used to analyze the data. The first was considering the socioeconomic variables and the second model was controlled by socioeconomic and behavioral variables (stress and symptoms of depression). Regarding the socioeconomic variables, systematic reviews have reported that age, income, skin color, and sex are important confounders in the association of obesity and dental caries ${ }^{4,6}$. Theoretically, stress and depression symptoms could be considered confounders and mediators of the relationship between $\mathrm{BMI}$ and tooth loss because they present a reciprocal link ${ }^{21}$. In other words, stress and depression can be considered as confounders because are associated with $\mathrm{BMI}^{21}$ and with dental caries ${ }^{12}$ and can be considered mediators because a decrease of BMI can decrease the risk of depression ${ }^{22,23}$ and depression could influence tooth loss ${ }^{24}$ (Figure 1). Therefore, we excluded behavioral variables from the second analysis considering this possibility. 


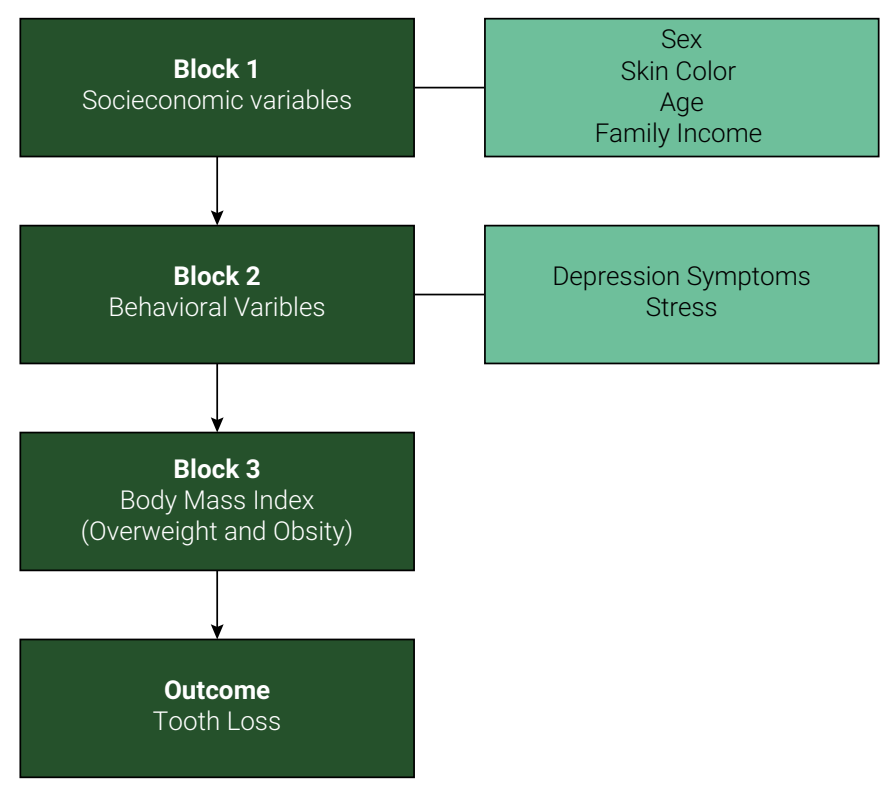

Figure 1. Theoretical model for analysis of association of overweight and obesity with tooth loss due to caries.

Sociodemographic variables were collected in the first block of the questionnaire. The sex of the participants was asked, as the age of individuals, which was categorized in $\leq 18,19$ to 34 , and 35 or more. Skin color variable was collected according to the Brazilian Institute of Geography and Statistics (IBGE) as white, light-black, dark-black, yellow, American Indian. They were categorized in white and non-white (light-black, dark-black, yellow, American Indian). Family income was collected categorically in Brazilian Reals (BRL): (a) up to 500; b) 501 up to 1,000; c) 1,001 up to 2,500; d) 2,501 up to 5,000; e) 5,001 up to 10,000; and f) more than 10,001) and stratified in three categories: a) $\leq 1,000$; b) 1,001 to 5,000 and c) $\geq 5,001$ Brazilian Reals.

Also, we have performed control in the second model by behavioral variables: symptoms of depression and stress. Symptoms of depression were assessed with Patient Health Questionnaire-2 (PHQ-2), an abbreviated version of the Patient Health Questionnaire Depression (PHQ-9) used for depression screening. The PHQ-2 is comprised of two questions about the frequency of depressive mood over the past two weeks. The PHQ-2 score ranges from 0 to 6 points and a cutoff of 3 was adopted. The stress level was measured with a modified version of the Perceived Stress Scale (PSS). The ten questions referred to the past month and present five answer options on a Likert scale (from score 1 to 5). Higher scores corresponded to an elevated level of stress and the variable was categorized in quartiles.

\section{Statistical methods}

Statistical analysis was performed with the software Stata 16.0 (Stata Corporation, College Station, TX, USA). Relative and absolute frequencies and the respective confidence interval of $95 \%$ (C195\%) of each variable of interest were estimated. The use of Poisson regression models for binary outcomes has been proposed and extensively 
applied in the last decade because it provides the estimation of prevalence or risk ratios instead of the odds ratio provided in the logistic model. We have chosen the multivariate Poisson model because the odds ratio can overestimate prevalence or risk ratio, complicating results interpretations. Also, Poisson regression with robust variance provides correct estimates for the analysis of binary outcomes and the prevalence or risk ratio is easier to interpret than the odds ratio. Moreover, independent variables were included in the multivariate model according to a theoretical model described in Figure 1.

Variables with $p$ values $\leq 0.250$ in the crude analyses were included in the adjusted model fitting. A backward stepwise procedure was used to include or exclude explanatory variables in the model fitting. Variables included in the final adjusted model should present a $\mathrm{p}$-value of $\leq 0.250$. For the final model, variables were considered significant if they had a p-value of $\leq 0.05$ after adjustments. Prevalence ratios (PR) were obtained for tooth loss and effect measure was estimated with $95 \%$ confidence intervals (Cl 95\%).

\section{Results}

A total of 3,237 students enrolled in the university were considered eligible for the study. From these, 2,118 (65.4\%) students were found and invited to participate in the present study, since $34.6 \%$ of students did not attend classes for three consecutive weeks and were considered as losses. Further, 2,089 (64.5\%) individuals agreed to participate in this study, assigning the consent term. Only 29 students (1.4\%) did not agree to participate in the study.

The majority of the sample (54.0\%) was between 19 and 34 years old and $71.4 \%$ of students had a family income ranging from $1,001.00$ to $5,000.00$ BRL (Table 1). Regarding the behavioral variables, we observed that the most stressed students $(22.9 \%)$ presented scores of the Perceived Stress Scale ranging from 22 to 40, and around $16.3 \%$ of students presented depressive symptoms. Besides, almost $23 \%$ of students were overweighed and $8.4 \%$ were obese. Also, 362 individuals (17.5\%) reported having had at least one tooth extracted due to caries (Table 1).

Table 1. Description of the general characteristics of the sample $(n=2,089)$. Brazil, 2016

\begin{tabular}{lcc}
\hline Variable/Category & $\mathbf{n}$ & $\%$ \\
\hline Sex & & \\
\hline Male & 993 & 57.7 \\
\hline Female & 1,087 & \\
\hline Age (years) & \multicolumn{2}{l}{37.4} \\
\hline$\leq 18$ & 777 & 54.0 \\
\hline 19 to 34 & 1,125 & 8.6 \\
\hline$\geq 35$ & 178 & \\
\hline Skin Color & & 74.8 \\
\hline White & 1,530 & 25.2 \\
\hline Non-white & 515 & Continue
\end{tabular}


Continuation

\begin{tabular}{lcc}
\hline Family income (BRL) & & \\
\hline$\leq 1000$ & 280 & 16.3 \\
\hline 1001 to 5000 & 1,057 & 22.13 \\
\hline$\geq 5001$ & 380 & \\
\hline Depression symptoms & & 83.7 \\
\hline No & 1,743 & 16.3 \\
\hline Yes & 339 & \\
\hline Stress (quartile) & & 26.3 \\
\hline $1^{\text {nd }}$ (PSS scores 0 - 11) & 550 & 27.3 \\
\hline $2^{\text {nd }}$ (PSS scores 12 - 16) & 571 & 23.4 \\
\hline $3^{\text {rd }}$ (PSS scores 17 - 21) & 489 & 22.9 \\
\hline $4^{\text {rd }}$ (PSS scores 22 - 40) & 479 & 68.8 \\
\hline Body Mass Index & & 22.8 \\
\hline Eutrophic & 1,387 & 8.4 \\
\hline Overweight & 460 & 82.5 \\
\hline Obesity & 169 & 17.5 \\
\hline Tooth Loss due to caries & & \\
\hline No & 1,710 & 362 \\
\hline Yes & & \\
\hline
\end{tabular}

In table 2, the crude and adjusted prevalence ratio for the association of body mass index and tooth loss due to caries is displayed. In the final model adjusted by behavioral variables, obese university students presented a $32.0 \%$ higher prevalence of tooth loss (PR $=0.32$, CI95\% [1.17 - 1.49]). However, overweight was not associated with tooth loss in this model (PR $=1.01 ; \mathrm{Cl} 95 \%[0.91-1.13])$. When the model was not associated by behavioral variables, overweight was associated with tooth loss $(P R=1.44 ; \mathrm{Cl} 95 \%[1.15-1.81])$ just as obesity $(\mathrm{PR}=2.13 ; \mathrm{Cl} 95 \%[1.63-2.78])$.

Table 2. Crude $\left(^{c}\right)$ and adjusted $\left({ }^{a}\right)$ prevalence ratio (PR) for association of body mass index and tooth loss control by independent variables. Pelotas, RS, Brazil. Poisson Regression ( $n=1902)$. Brazil, 2016.

\begin{tabular}{|c|c|c|c|c|c|c|}
\hline Variable/Category & $\mathrm{PR}^{\mathrm{c}}(\mathrm{Cl} 95 \%)$ & p-Value & $\mathrm{PR}^{\mathrm{a} 1}(\mathrm{Cl} 95 \%)$ & $\mathrm{p}$-Value & $\mathrm{PR}^{\mathrm{a} 2}(\mathrm{Cl} 95 \%)$ & p-Value \\
\hline Sex (ref=Male) & & 0.702 & & - & & 0.231 \\
\hline Female & $0.98(0.900-1.07)$ & & - & & $1.13(0.92-1.38)$ & \\
\hline Skin Color (ref=white) & & 0.009 & & 0.009 & & 0.181 \\
\hline Non-white & $1.13(1.03-1.24)$ & & $1.13(1.03-1.24)$ & & $0.85(0.68-1.07)$ & \\
\hline Age (years) (ref=16 to 17$)$ & & 0.972 & & - & & - \\
\hline 18 to 24 & $1.05(0.93-1.19)$ & & - & & - & \\
\hline 25 to 34 & $1.01(0.85-1.21)$ & & & & & \\
\hline 35 or more & $1.02(0.84-1.22)$ & & & & & \\
\hline Family income $($ ref $=\leq 1000)$ & & 0.069 & & - & & $<0.001$ \\
\hline 1001 to 5000 & $0.98(0.87-1.11)$ & & - & & $1.93(1.35-2.7)$ & \\
\hline$\geq 5001$ & $0.88(0.75-1.02)$ & & & & $2.85(1.98-2.70)$ & \\
\hline
\end{tabular}


Continuation

\begin{tabular}{|c|c|c|c|c|c|c|}
\hline \multicolumn{2}{|l|}{$\begin{array}{l}\text { Depression symptoms } \\
\text { (ref=No) }\end{array}$} & \multicolumn{2}{|l|}{0.001} & & & \\
\hline Yes & $1.18(1.07-1.31)$ & & - & & & \\
\hline $\begin{array}{l}\text { Stress (quartile) } \\
\text { (ref=1st - PSS scores } 0-11 \text { ) }\end{array}$ & & $<0.001$ & & $<0.001$ & & \\
\hline $2^{\text {nd }}(P S S$ scores $12-16)$ & $1.19(1.05-1.35)$ & & $1.19(1.05-1.35)$ & & & \\
\hline $3^{\text {rd }}$ (PSS scores $\left.17-21\right)$ & $1.27(1.12-1.44)$ & & $1.26(1.11-1.44)$ & & & \\
\hline $4^{\text {rd }}($ PSS scores $22-40)$ & $1.30(1.15-1.48)$ & & $1.29(1.13-1.46)$ & & & \\
\hline $\begin{array}{l}\text { Body Mass Index } \\
\text { (ref= Eutrophic) }\end{array}$ & & 0.001 & & 0.001 & & $<0.001$ \\
\hline Overweight & $1.01(0.91-1.13)$ & & $1.01(0.91-1.13)$ & & $1.44(1.15-1.81)$ & \\
\hline Obesity & $1.32(1.16-1.49)$ & & $1.32(1.17-1.49)$ & & $2.13(1.63-2.78)$ & \\
\hline
\end{tabular}

${ }^{\mathrm{a} 1}$ included behavioral variables in the model; a2 behaviorall variables were not included in the model

\section{Discussion}

Tooth loss and obesity are significant health issues, affecting an elevated number of individuals worldwide ${ }^{15}$. The previous studies that evaluate the relationship between obesity and tooth loss have only considered the periodontal disease as a causal factor for tooth loss, disregarding losses due to caries ${ }^{15,25}$. In the present study, it was hypothesized that tooth loss due to caries can be influenced by obesity or overweight. In the examined sample of university students, obese individuals presented a higher prevalence of tooth loss due to caries and overweight individuals only showed this association when the model was not adjusted by behavioral variables, possibly due to a mediator effect of depressive symptoms.

The main explanation of the connection between tooth loss due to caries and obesity is the highly cariogenic diet of obese individuals mainly in industrialized countries ${ }^{8}$. Beyond a lipid-rich diet, obese individuals frequently have a sugar and carbohydrate-rich $\operatorname{diet}^{26}$, which is a prominent factor for the development and proliferation of caries ${ }^{8}$. Also, some studies have demonstrated that a decrease of salivary flow is observed in individuals with a body mass index higher than $25^{27}$. Thus, a decrease of salivary flow can be observed in obese individuals, potentially increasing the progression of caries and conducting to tooth loss. This occurs because of the low-grade and generalized inflammation caused by obesity, which influences immune mediators such as proinflammatory cytokines $^{28}$. The cytokines and the hypothalamic-pituitary-adrenal axis can modulate the central nervous system function and decrease the salivary flow ${ }^{27}$.

The relation between caries and obesity is not well established, considering the conflicting results, maybe because BMI cannot distinguish fat mass, muscle, and bone mass, 10,16,17. However, this is a simple and accessible tool for obesity and overweight measurement, employed in most epidemiological studies. When the etiological factors of the disease are not treated, a progression of caries is expected ${ }^{29}$, which can lead to tooth loss.

Systematic reviews have presented conflicting results regarding the presence of a positive association between obesity and dental caries ${ }^{6,30}$ and the studies have not investigated the relationship between obesity or overweight and tooth loss due to car- 
ies. Generally, the studies have investigated the association of BMI with DMFT-index and not considered only the tooth loss due to caries ${ }^{27,31-34}$. A study carried out in Chile considered only the decayed teeth, not those restored or extracted due to caries, and have not observed association with obesity ${ }^{35}$. On the other hand, our study included only tooth loss and did not include decayed teeth. Therefore, we included in our outcome the most severe caries experience and its factor could be responsible for differences observed among the studies. Corroborating, Silva et al. ${ }^{6}$ related that both methods of diagnosis (to BMI and caries) probably influenced the results observed in the review: i.e., some studies used more sensible to diagnosis caries as interproximal radiography ${ }^{36,37}$; and all studies included in the systematic review ${ }^{6}$ used BMI to measure obesity/overweight, but using different cut-offs. These findings indicate that the way in which obesity criteria are measured can be an important factor in the study's conclusions. Similarly, different adjustments in analytical models could be another important factor observed in the results of studies ${ }^{6}$.

In the present study, we tested two analytical models. In the first, we considered the possibility of behavioral variables (stress and depression) having confounders of the association between obesity/overweight and tooth loss, and observed that only obesity was associated, possible due to a mediation effect. On the other hand, when the analysis was not adjusted by symptoms of depression, both obesity and overweight were associated with tooth loss. Considering that the present study is cross-sectional and this is not the best design to investigate mediation variables, we did not explore possible mediation effects. Therefore, further studies with longitudinal design could be addressed to investigate this gap and explore the causal mechanism.

Although several variable adjustments were performed for the present analysis, we did not conduct diet intake control, being this one of the main frail points of the present study. In addition, the use of self-reported measures could be over or underestimated, as this is a subjective measurement. However, university students are barely investigated in the literature, consisting of an interesting sample for studies although it presents different features compared to the general population. Thus, extrapolation of the results to the general population must be avoided. Moreover, the self-reported oral health measurement used in the present study can vary in data accuracy compared to objectively measured data ${ }^{38}$. However, this approach is a valid tool widely used in epidemiologic studies, which promotes ease and quickness, aiming to reduce the time of examination and lowering the costs ${ }^{39,40}$. Beyond that, it is important to consider a probable underestimation of BMI, mainly in overweight and obese participants ${ }^{41,42}$. A significant number of eligible students did not participate in the study, although field teamwork returned for three consecutive weeks in classrooms. Thus, the losses were mainly caused by the impossibility of the location of individuals in their respective classrooms. However, similar questionnaire-based studies also showed this difficulty ${ }^{43}$.

Regardless, the present study evaluated a wide sample of individuals and presented control by socioeconomic and behavioral factors, being the first to evaluate psychosocial variables with the present outcome. Most of the studies found in the literature evaluate the association of obesity and tooth loss due to periodontal disease ${ }^{25}$. Nevertheless, the relationship between obesity and tooth loss due to caries is poorly investigated and was positively associated with the present study. 
Therefore, obesity and overweight were associated with tooth loss due to caries in the present sample of university students. Overweight lost the association when the analysis was adjusted by behavioral variables. These findings suggest underlining causal mechanisms that can be explored in further studies, preferably carried out with a longitudinal design. Moreover, further studies could explore the bidirectional effects of the association of obesity and tooth loss.

\section{Compliance with Ethical Standards}

Conflict of interest: The authors declare that there is no conflict of interest.

Ethical approval: All procedures performed in studies involving human participants were in accordance with the ethical standards of the institutional and/or national research committee and with the 1964 Helsinki declaration and its subsequent amendments, or comparable ethical standards.

Informed consent: Informed consent was obtained from all individuals participating in the study or their legal responsible ( $<18$ years).

\section{References}

1. Collaboration NCDRF. Worldwide trends in body-mass index, underweight, overweight, and obesity from 1975 to 2016: a pooled analysis of 2416 population-based measurement studies in 128.9 million children, adolescents, and adults. Lancet. 2017 Dec 16;390(10113):2627-42. doi: 10.1016/S0140-6736(17)32129-3.

2. Falagas ME, Kompoti M. Obesity and infection. Lancet Infect Dis. 2006 Jul;6(7):438-46. doi: 10.1016/S1473-3099(06)70523-0.

3. Peeters A, Barendregt JJ, Willekens F, Mackenbach JP, Al Mamun A, Bonneux L, et al. Obesity in adulthood and its consequences for life expectancy: a life-table analysis. Ann Intern Med. 2003 Jan;138(1):24-32. doi: 10.7326/0003-4819-138-1-200301070-00008.

4. Hayden C, Bowler JO, Chambers S, Freeman R, Humphris G, Richards D, et al. Obesity and dental caries in children: a systematic review and meta-analysis. Community Dent Oral Epidemiol. 2013 Aug;41(4):289-308. doi: 10.1111/cdoe.12014.

5. World Health Organization. Consideration of the evidence on childhood obesity for the Commission on Ending Childhood Obesity: report of the Ad hoc Working Group on Science and Evidence for Ending Childhood Obesity. Geneva: WHO; 2016.

6. Silva AE, Menezes AM, Demarco FF, Vargas-Ferreira F, Peres MA. Obesity and dental caries: systematic review. Rev Saude Publica. 2013 Aug;47(4):799-812. doi: 10.1590/S0034-8910.2013047004608.

7. Chisini LA, Cademartori MG, Conde MCM, Costa FDS, Salvi LC, Tovo-Rodrigues L, et al. Single nucleotide polymorphisms of taste genes and caries: a systematic review and meta-analysis. Acta Odontol Scand. 2020 Oct 25;1-9. doi: 10.1080/00016357.2020.1832253.

8. Peres MA, Sheiham A, Liu P, Demarco FF, Silva AE, Assuncao MC, et al. Sugar consumption and changes in dental caries from childhood to adolescence. J Dent Res. 2016 Apr;95(4):388-94. doi: $10.1177 / 0022034515625907$.

9. Paisi M, Kay E, Kaimi I, Witton R, Nelder R, Christophi C, et al. Obesity and dental caries in young children in Plymouth, United Kingdom: a spatial analysis. Community Dent Health. 2018 Mar;35(1):58-64. doi: 10.1922/CDH_4214Paisi07. 
10. Paisi M, Kay E, Kaimi I, Witton R, Nelder R, Potterton R, et al. Obesity and caries in four-to-six year old English children: a cross-sectional study. BMC Public Health. 2018 Feb;18(1):267. doi: 10.1186/s12889-018-5156-8.

11. Lock NC, Susin C, Brusius CD, Maltz M, Alves LS. Obesity and dental caries among South Brazilian schoolchildren: a 2.5-year longitudinal study. Braz Oral Res. 2019 Jul;33:e056. doi: 10.1590/1807-3107bor-2019.vol33.0056.

12. Fernandez MR, Goettems ML, Demarco FF, Correa MB. Is obesity associated to dental caries in Brazilian schoolchildren? Braz Oral Res. 2017 Nov;31:e83. doi: 10.1590/1807-3107BOR-2017.vol31.0083.

13. Alves LS, Susin C, Dame-Teixeira N, Maltz M. Overweight and obesity are not associated with dental caries among 12-year-old South Brazilian schoolchildren. Community Dent Oral Epidemiol. 2013 Jun;41(3):224-31. doi: 10.1111/cdoe.12010.

14. Peltzer K, Pengpid S. The Association of Dietary Behaviors and Physical Activity Levels with General and Central Obesity among ASEAN University Students. AIMS Public Health. 2017 Jun 23:4(3):301-13. doi: 10.3934/publichealth.2017.3.301.

15. Nascimento GG, Leite FR, Conceicao DA, Ferrua CP, Singh A, Demarco FF. Is there a relationship between obesity and tooth loss and edentulism? A systematic review and meta-analysis. Obes Rev. 2016 Jul;17(7):587-98. doi: 10.1111/obr.12418.

16. Costacurta M, DiRenzo L, Sicuro L, Gratteri S, De Lorenzo A, Docimo R. Dental caries and childhood obesity: analysis of food intakes, lifestyle. Eur J Paediatr Dent. 2014 Dec;15(4):343-8.

17. Alghamdi AA, Almahdy A. Association Between Dental Caries and Body Mass Index in Schoolchildren Aged Between 14 and 16 Years in Riyadh, Saudi Arabia. J Clin Med Res. 2017 Dec;9(12):981-6. doi: 10.14740/jocmr2958w.

18. Chisini LA, Cademartori MG, Collares K, Tarquinio SBC, Goettems ML, demarco FF, et al. Methods and logistics of an oral health cohort of university students from Pelotas, a Brazilian Southern city. Braz J Oral Sci. 2019;18:e191460. doi: 10.20396/bjos.v18i0.8655316.

19. Chisini LA, Cademartori MG, Collares K, Pires ALC, Correa MB, demarco FF. Desire of university students for esthetic treatment and tooth bleaching: a cross-sectional study. Braz J Oral Sci. 2019;18:e191648. doi: 10.20396/bjos.v18i0.8657267.

20. World Health Organization. Obesity: preventing and managing the global epidemic. Geneva: WHO; 2000.

21. Luppino FS, de Wit LM, Bouvy PF, Stijnen T, Cuijpers P, Penninx BW, et al. Overweight, obesity, and depression: a systematic review and meta-analysis of longitudinal studies. Arch Gen Psychiatry. 2010 Mar;67(3):220-9. doi: 10.1001/archgenpsychiatry.2010.2.

22. Speed MS, Jefsen OH, Borglum AD, Speed D, Ostergaard SD. Investigating the association between body fat and depression via Mendelian randomization. Transl Psychiatry. 2019 Aug;9(1):184. doi: 10.1038/s41398-019-0516-4.

23. Tyrrell J, Mulugeta A, Wood AR, Zhou A, Beaumont RN, Tuke MA, et al. Using genetics to understand the causal influence of higher BMI on depression. Int J Epidemiol. 2019 Jun;48(3):834-48. doi: $10.1093 /$ ije/dyy223.

24. Arora G, Humphris G, Lahti S, Richards D, Freeman R. Depression, drugs and dental anxiety in prisons: A mediation model explaining dental decay experience. Community Dent Oral Epidemiol. 2020 Jun;48(3):248-55. doi: 10.1111/cdoe.12522.

25. Prpic J, Kuis D, Glazar I, Ribaric SP. Association of obesity with periodontitis, tooth loss and oral hygiene in non-smoking adults. Cent Eur J Public Health. 2013 Dec;21(4):196-201.

26. Brouns F. Overweight and diabetes prevention: is a low-carbohydrate-high-fat diet recommendable? Eur J Nutr. 2019 Apr;58(3):1339. doi: 10.1007/s00394-019-01959-w. 
27. Modeer T, Blomberg CC, Wondimu B, Julihn A, Marcus C. Association between obesity, flow rate of whole saliva, and dental caries in adolescents. Obesity (Silver Spring). 2010 Dec;18(12):2367-73. doi: $10.1038 /$ oby.2010.63.

28. Zhu Q, Scherer PE. Immunologic and endocrine functions of adipose tissue: implications for kidney disease. Nat Rev Nephrol. 2018 Feb;14(2):105-20. doi: 10.1038/nrneph.2017.157.

29. Chisini LA, Collares K, Cademartori MG, de Oliveira LJC, Conde MCM, Demarco FF, et al. Restorations in primary teeth: a systematic review on survival and reasons for failures. Int J Paediatr Dent. 2018 Mar;28(2):123-39. doi: 10.1111/ipd.12346.

30. Kantovitz KR, Pascon FM, Rontani RM, Gaviao MB. Obesity and dental caries--A systematic review. Oral Health Prev Dent. 2006;4(2):137-44.

31. Marshall TA, Eichenberger-Gilmore JM, Broffitt BA, Warren JJ, Levy SM. Dental caries and childhood obesity: roles of diet and socioeconomic status. Community Dent Oral Epidemiol. 2007 Dec;35(6):449-58. doi: 10.1111/j.1600-0528.2006.00353.x.

32. Willerhausen B, Blettner M, Kasaj A, Hohenfellner K. Association between body mass index and dental health in 1,290 children of elementary schools in a German city. Clin Oral Investig. 2007 Sep;11(3):195-200. doi: 10.1007/s00784-007-0103-6.

33. Pinto A, Kim S, Wadenya R, Rosenberg H. Is there an association between weight and dental caries among pediatric patients in an urban dental school? A correlation study. J Dent Educ. 2007 Nov;71(11):1435-40.

34. Kopycka-Kedzierawski DT, Auinger P, Billings RJ, Weitzman M. Caries status and overweight in 2- to 18-year-old US children: findings from national surveys. Community Dent Oral Epidemiol. 2008 Apr;36(2):157-67. doi: 10.1111/j.1600-0528.2007.00384.x.

35. Cereda MA, Faleiros SC, A.Q. O, Pinto GM, Tapia VR, Díaz CS, et al. [Prevalence of Dental decay in elementary school children and association with nutritional status]. Rev Chil Pediatr. 2010 Feb;81(1):28-36. doi: 10.4067/S0370-41062010000100004. Spanish.

36. Alm A, Fahraeus C, Wendt LK, Koch G, Andersson-Gare B, Birkhed D. Body adiposity status in teenagers and snacking habits in early childhood in relation to approximal caries at 15 years of age. Int J Paediatr Dent. 2008 May;18(3):189-96. doi: 10.1111/j.1365-263X.2007.00906.X.

37. Alm A, Isaksson H, Fahraeus C, Koch G, Andersson-Gare B, Nilsson M, et al. BMI status in Swedish children and young adults in relation to caries prevalence. Swed Dent J. 2011;35(1):1-8.

38. Bhandari A, Wagner T. Self-reported utilization of health care services: improving measurement and accuracy. Med Care Res Rev. 2006 Apr;63(2):217-35. doi: 10.1177/1077558705285298.

39. Silva AE, Menezes AM, Assuncao MC, Goncalves H, Demarco FF, Vargas-Ferreira F, et al. Validation of self-reported information on dental caries in a birth cohort at 18 years of age. PLoS One. 2014 Sep 9;9(9):e106382. doi: 10.1371/journal.pone.0106382.

40. Silva FBD, Chisini LA, Demarco FF, Horta BL, Correa MB. Desire for tooth bleaching and treatment performed in Brazilian adults: findings from a birth cohort. Braz Oral Res. 2018 Mar;32:e12. doi: 10.1590/1807-3107bor-2018.vol32.0012.

41. Sherry B, Jefferds ME, Grummer-Strawn LM. Accuracy of adolescent self-report of height and weight in assessing overweight status: a literature review. Arch Pediatr Adolesc Med. 2007 Dec;161(12):1154-61. doi: 10.1001/archpedi.161.12.1154.

42. Maukonen M, Mannisto S, Tolonen H. A comparison of measured versus self-reported anthropometrics for assessing obesity in adults: a literature review. Scand J Public Health. 2018 Jul;46(5):565-79. doi: 10.1177/1403494818761971.

43. Chisini LA, Conde MC, Correa MB, Dantas RV, Silva AF, Pappen FG, et al. Vital pulp therapies in clinical practice: findings from a survey with dentist in Southern Brazil. Braz Dent J. 2015;26(6):566-71. doi: 10.1590/0103-6440201300409. 